\title{
Triple funcionalidad del empresario: socio, directivo y asalariado. Un enfoque administrativo y jurídico
}

\author{
The entrepreneur's triple functionality: shareholder, member of the board of \\ directors and employee. An administrative and legal approach
}

DOI: $10.22458 /$ rna.v12i1.3362

Dr. Juan Diego Sánchez Sánchez, Ph.D

${ }^{1}$ Universidad Latina de Costa Rica, Escuela de Tecnologías de Información y Comunicación,

San José, Costa Rica; juan.sanchez6@ulatina.net, https://orcid.org/0000-0002-3168-210X

\section{RESUMEN}

El artículo aborda la figura empresarial y jurídica denominada como triple funcionalidad del empresario, la cual es dada por la existencia de las tres condiciones específicas y simultaneas en una misma persona: socio, miembro de la junta directiva y asalariado en la misma empresa. El abordaje hecho de esta figura es precisado desde un enfoque administrativo y jurídico, en el cual se analizan los elementos legales y operativos de cada una de las tres condiciones existentes en la figura del empresario, así como las posibles discrepancias jurídicas y técnicas que pueden darse para las tres posiciones definidas. Se efectúa un análisis de la normativa existente en el país, así como las interpretaciones que las autoridades gubernamentales hacen del tema. Se finaliza con una propuesta de regulación que sirva como un modelo que brinde certeza jurídica al empresario.

\begin{abstract}
This paper addresses the business and legal figure referred to as the entrepreneur's triple functionality based on three specific and simultaneous capacities of the same person: shareholder, member of the board of directors and employee of the same company. The approach to this figure is made accurate by an administrative and legal analysis, in which the legal and operational elements of each of the three conditions are analyzed, as well as the possible legal and technical discrepancies that may arise for the three defined positions. An analysis of the current regulations in the country is carried out, as well as the interpretations made by the government authorities on the topic. This paper ends with a regulation proposal that serves as a model to provide legal certainty to the entrepreneur.
\end{abstract}

\section{RÉSUMÉ}

L'article aborde la figure entrepreneuriale et juridique connue comme la triple fonctionnalité de l'entrepreneur, qui est fondée sur les trois qualités spécifiques et simultanées chez une même personne : partenaire, membre du conseil d'administration et employé auprès de la même société. L’abordage de cette figure est précisé à partir d'une analyse administrative et juridique, dans laquelle les éléments juridiques et opérationnels de chacune des trois qualités existantes sont examinés dans la figure de l'entrepreneur, de même que les possibles divergences juridiques et techniques qui peuvent surgir pour les positions définies. Une analyse de la réglementation actuelle est effectuée dans le pays de même que les interprétations faites par les autorités gouvernementales à ce sujet. L'article conclut avec une proposition de régulation qui serve de modèle donnant une assurance juridique à l'entrepreneur.

\section{RESUMO}

$\mathrm{O}$ artigo trata a figura empresarial e jurídica denominada como tripla funcionalidade do empresário, a qual dá-se pela existência das três condições específicas e simultâneas na mesma pessoa: sócio, membro da diretoria e assalariado da mesma empresa. A abordagem feita desta figura é requerida a partir de um enfoque administrativo e jurídico, em que são analisados os elementos legais e operacionais de cada uma das três condições existentes na figura do empresário, bem como as possíveis discrepâncias jurídicas e técnicas que possam ocorrer para as três posições definidas. É feita uma análise da normativa existente no país, bem como das interpretações que as autoridades governamentais fazem sobre o tema. Concluise com uma proposta de regulamentação que seja um modelo que ofereça segurança jurídica ao empresário.

\section{PALABRAS CLAVE:}

ADMINISTRACIÓN, EMPRESA, EMPRESARIO, SOCIO, JUNTA DIRECTIVA, ASALARIADO, GESTIÓN EMPRESARIAL, DERECHO EMPRESARIAL.

\section{KEYWORDS:}

ADMINISTRATION,

COMPANY,

ENTREPRENEUR,

SHAREHOLDER, BOARD

OF DIRECTORS,

EMPLOYEE, BUSINESS

MANAGEMENT,

CORPORATIVE LAW.
MOTS-CLÉS:

ADMINISTRATION,

ENTREPRISE,

ENTREPRENEUR,

PARTENAIRE, CONSEIL

D'ADMINISTRATION,

EMPLOYÉ, GESTION

D'ENTREPRISE, DROIT DES

SOCIÉTÉS.
PALAVRAS-CHAVE:

ADMINISTRAÇÃO,

EMPRESA, EMPRESÁRIO,

SÓCIO, DIRETORIA,

ASSALARIADO, GESTÃO

DE NEGÓCIOS, DIREITO

EMPRESARIAL. 


\section{INTRODUCCIÓN}

El presente trabajo detalla las tres diferentes funciones o bien posiciones formales que una persona, en su calidad de propietario de una empresa, pudiese tener en ella; esto desde una óptica del derecho laboral, pero ligado a los elementos propios de la administración y gestión societarias y con un ligamen particular al derecho tributario, ya que, cuando se aborda la denominada triple funcionalidad del empresario, se hace frente a elementos que parecen ser contradictorios entre sí, al considerar las diferentes posiciones que puede tener la persona en la estructura empresarial en cuestión, principalmente desde un enfoque jurídico y administrativo.

La triple funcionalidad del empresario hace mención a la posibilidad material y real de que una persona ocupe simultáneamente las posiciones de socio propietario, miembro activo de la junta directiva y asalariado en la misma estructura empresarial y societaria. En este último caso, usualmente la persona es nombrada como gerente general.

La situación en cuestión parece ser de interés sobre todo al ser analizada desde la óptica de lo expresamente permitido con respecto a la no precisión de su posibilidad; esto, pues, como se analiza más adelante, la figura como tal, aunque no está expresamente prohibida por el ordenamiento jurídico, tampoco es regulada de manera explícita, lo cual ocasiona diversas interpretaciones doctrinarias y prácticas, ocasionando en varios casos discrepancias de interés entre las aplicaciones que puedan darse.

Temas tales como las interpretaciones que los ministerios y las instancias jurídicas involucrados puedan dar al tema toman especial relevancia al darse lo que parece ser una interpretación contraria en material laboral y tributaria, de forma que se sustenta en mayor medida la necesidad de su estudio y la ponderación de una u otra posición.

$\mathrm{El}$ aspecto anterior se deriva de la inexistencia de una norma expresa que permita este funcionamiento propio de las empresas, en particular de aquellas empresas pequeñas en las cuales el dueño suele ser a la vez directivo y, en búsqueda de un control directo, suele también fungir como gerente. De acá el abordaje que se hace en el presente trabajo, así como las recomendaciones pertinentes para su posible regulación y, por ende, la generación de una mayor y mejor certeza jurídica al empresario.

\section{TRIPLE FUNCIONALIDAD EMPRESARIAL}

\section{Descripción}

Si bien el concepto como tal no parece obtener su sustento en la doctrina jurídica, pues no parece precisarse una definición específica, sí puede definirse como una mezcla simultánea de la ocupación y ejercicio de tres posiciones a la vez dentro de una sociedad mercantil por parte de la misma persona (Sánchez, 2020). Rodríguez (2018) expresa un concepto de interés relacionado con el tema:

Es muy habitual que los socios de las sociedades mercantiles sean además trabajadores de la empresa. El hecho de que la sociedad tenga personalidad jurídica propia implica que los socios y la sociedad son independientes y pueden celebrarse contratos entre ellos independientemente de la vinculación existente. Otra cosa es qué tipo de relación legal existe y como debe ponerse en práctica la realización de tareas que, como trabajadores, llevan a cabo estos para el desarrollo del negocio. (Rodríguez, 2018, párr.1)

Puede observarse lo usual de que una misma persona física presente diferentes posiciones dentro del poder y la estructura societaria. Por lo tanto, puede definirse que la triple funcionalidad se refiere al hecho de que una misma persona física ocupe y ejerza a la vez las posiciones de socio accionista, miembro activo de la junta directiva de la sociedad y asalariado.

La figura en cuestión es dada para cualquier tipo de sociedad mercantil de capital, es decir, las sociedades anónimas o sociedades de responsabilidad limitada. Y, aunque la existencia de las tres calidades en cuestión (socio, directivo y asalariado) puede presentarse en cualquier empresa, sin importar su tamaño, es más usual en las denominadas pymes (pequeñas y medianas empresas), donde es común que el empresario sea socio, cuente con un nombramiento en la junta directiva y desee ser gerente en su empresa, para contar así con un salario. 


\section{Socio}

Herrero (2012) explica que la sociedad mercantil es "constituida por uno o más socios, cuyo capital social, integrado por las aportaciones de los socios [...] está dividido en acciones, que son unos títulos que pueden transmitirse libremente" (p. 23). Es decir, se trata de la persona que es propietario legítimo de una proporción o de la totalidad de las acciones de una sociedad, lo cual le brinda la facultad de ejercer el poder de toma de decisiones a nivel de asamblea de socios, entendido este como el órgano máximo del poder societario, en función de la cantidad y proporción porcentual de acciones de las cuales sea tenor.

El socio puede definirse como mayoritario si tiene en su haber al menos el $51 \%$ de la totalidad de las acciones emitidas por la sociedad, lo cual le da el poder de la toma de decisiones por sí mismo. Si un socio posee una cantidad menor al porcentaje señalado, se define como socio minoritario, lo cual implica que no puede tomar decisiones por sí solo, pues estas, al menos a nivel societario, requieren mayoría simple, es decir, el $51 \%$ del capital accionario, indiferentemente de cómo se repartan los porcentajes de acciones entre los socios.

También puede observarse el concepto en el artículo 140 del Código de Comercio, el cual indica lo siguiente: "La sociedad considerará como socio al inscrito como tal en los registros de accionistas" (Asamblea Legislativa de Costa Rica, 2019b, párr.1).

Es importante señalar que el socio no tiene una relación contractual formal con la empresa, es decir, no se señala una relación laboral directa; el ligamen que tiene con la empresa es dado por un derecho de propiedad sobre la proporción de las acciones de las cuales el socio en cuestión sea el dueño (Monge, 2014).

\section{Directivo}

La existencia de la junta directiva es derivada de la misma creación de la sociedad mercantil y esta es nombrada precisamente por la asamblea de socios ordinaria (Monge, 2014). Es decir, su existencia y génesis se derivan del órgano de máximo poder directivo en las sociedades mercantiles.

La junta directiva debe tener al menos el nombramiento expreso de un presidente, un secretario y un tesorero, siendo estas las posiciones que como mínimo deben existir, aunque se permite la creación de posiciones adicionales, siempre que sean aprobadas por la asamblea de socios, tal cual señala Monge (2014).

Lo anterior puede observarse en el Código de Comercio (2019), numeral 181:

Los negocios sociales serán administrados y dirigidos por un consejo de administración o una junta directiva, que deberá estar formada por un mínimo de tres miembros, quienes podrán ser o no socios y ostentar las calidades de presidente, secretario y tesorero. Salvo norma contraria en los estatutos, en la elección de consejeros, los accionistas ejercerán su voto por el sistema de voto acumulativo, así:

a). Cada accionista tendrá un mínimo de votos igual al que resulte de multiplicar los votos que normalmente le hubiesen correspondido por el número de consejeros por elegirse.

b). Cada accionista podrá distribuir o acumular sus votos en un número de candidatos igual o inferior al número de vacantes por cubrir, en la forma que juzgue conveniente.

c). El resultado de la votaci ón se computará por persona.

El Consejo no podrá renovarse parcial ni escaladamente, si de esta manera se impide el ejercicio del voto acumulativo. (Asamblea Legislativa de Costa Rica, 2019b, párr.1)

Adicionalmente, según precisa Rodríguez (2018), el directivo no tiene una relación de índole laboral con la empresa, sino que cuenta con un nombramiento realizado por la asamblea de socios, la cual otorga las competencias a la persona para fungir como miembro de la junta directiva; es decir, le brinda cierta autoridad para la toma de decisiones operativas ligadas a la gestión del giro de negocio. 


\section{Asalariado}

Entendido también como empleado y definido como quien "ejecuta una tarea o presta un servicio con sujeción a otra persona, voluntaria o forzosamente, contra un salario o medio de subsistencia” (Cabanellas, 2001, p. 267). Esta figura responde a la existencia de un vínculo laboral y, por ende, a un determinado contrato escrito o verbal, que deriva en todas las responsabilidades propias de esta figura (Goerlich et al., 2010).

Claramente, en este caso sí se precisa una evidente relación contractual y de naturaleza laboral de la persona con la empresa, donde la primera es definida como empleado y está sujeta a la segunda bajo el principio de subordinación, donde la empresa se define como el patrono (Goerlich et al., 2010).

Como parte de esta figura, se observan aspectos como el cumplimiento y pago de las cargas sociales, así como los correspondientes derechos laborales tales como aguinaldo, vacaciones, preaviso y cesantía, entre otros.

\section{Funcionamiento administrativo de cada figura empresarial}

Tal cual se señala antes, la triple funcionalidad empresarial denota la existencia de tres figuras diferentes y cada una genera una relación contractual, una carga y un pago diferenciados, que se explican a continuación.

\section{En relación con el socio}

La posición del socio es derivada de la tenencia y propiedad sobre las acciones comunes, las cuales le brindan la capacidad de ejercer votos de acuerdo con su proporcionalidad. También cuenta con el derecho de recibir el pago por concepto de dividendos, los cuales son calculados con base en las utilidades acumuladas (Sansonetti, 2020) y en función de la política que la asamblea de socios defina.

Este pago conlleva la obligación tributaria de un impuesto sobre la renta del $15 \%$, con base en la Ley de Impuesto Sobre la Renta, el cual debe ser retenido por la sociedad que cancela el dividendo, para ser liquidado posteriormente con el formulario de retenciones en la fuente. Es de relevancia señalar aquí que no existe exoneración alguna en materia de este impuesto cuando sea cancelado a socios que sean personas físicas, pues todo socio que desee recibir el dividendo en cuestión se torna sujeto pasivo de la renta de capital al pago por dividendos (Asamblea Legislativa de Costa Rica, 2019a).

No existe relación laboral entre la sociedad y el socio; este último solo cumple las funciones de ser el tomador de decisiones final en asambleas ordinarias o extraordinarias, siendo parte de este órgano máximo del poder societario.

\section{En relación con el directivo}

Los miembros de junta directiva son nombrados por la asamblea de socios, por medio de una asamblea extraordinaria, así definido en el inciso c del artículo 155 del Código de Comercio (Asamblea Legislativa de Costa Rica, 2019b). Los directivos en cuestión representan el órgano supervisor del funcionamiento propio de la empresa, es decir, una especie de órgano administrativo, el cual se encarga de la gestión estratégica y fiscalizadora de las altas gerencias y la empresa como tal (Herrero, 2012).

La junta directiva está conformada por al menos un presidente, un secretario y un tesorero, así como otros puestos creados a discreción de la asamblea de socios. Estos individuos tienen el derecho de pago por concepto de una dieta, la cual debe ser previamente aprobada por la misma asamblea de socios y luego respaldada por las actas que demuestren las sesiones de esta junta, en el correspondiente libro de actas (Monge, 2014).

El pago por concepto de dietas conlleva una carga tributaria de un $15 \%$ cancelable de igual forma por retención en la fuente (Torrealba, 2009). Sin embargo, esto no implica la existencia de relación laboral alguna entre la sociedad y el directivo, ya que la responsabilidad de este último solo es dada por la necesidad de asistir y emitir su criterio y voto en las reuniones o sesiones de junta directiva, sin presentar los elementos propios de un contrato laboral. Al igual que en el impuesto derivado del pago de dividendos, no se contempla ninguna exoneración de este tributo. 


\section{En relación con el asalariado}

Se define el salario como la "retribución por unidad de tiempo o de obra [...] En todo caso, habida cuenta que el salario base constituye la contraprestación más directa a la prestación misma del trabajo” (Llompart, 2007, p. 539). $\mathrm{El}$ asalariado es una persona en cualquier puesto específico creado en la empresa y con la cual la sociedad empleadora tiene un vínculo laboral, donde se respetan los conceptos básicos de este tipo de contrato: prestación, subordinación, contraprestación y ajenidad (Goerlich et al., 2010).

Esta persona sí tiene una evidente relación de índole laboral con la sociedad y cuenta a su vez con el derecho al pago de un salario por las funciones realizadas como parte de su contrato laboral. En este caso, se está frente a una relación que conlleva el pago de cargas sociales y los derechos propios del contrato en cuestión (Fernández, 2014). De igual forma, según la Ley del Impuesto Sobre la Renta, si la persona tiene un salario mayor a los ochocientos cuarenta mil colones, también se tiene la obligación de cancelar un impuesto de renta al salario, el cual se calcula de forma escalonada y cuyas tasas impositivas van desde el 10 \% hasta el $25 \%$ (Asamblea Legislativa de Costa Rica, 2019a).

\section{Entes involucrados en la triple funcionalidad del empresario}

Se han señalado las figuras incluidas en la triple funcionalidad del empresario. Ahora bien, al existir una pluralidad de estas posiciones y al verse involucradas diversas ramas del derecho y la administración, así como del ordenamiento jurídico, de igual forma se observan algunos entes de interés involucrados en el proceso.

\section{Sociedad mercantil}

El primer ente involucrado en esta triple funcionalidad es la sociedad mercantil, en la cual se da la función en las tres áreas mencionadas. En este caso, la sociedad o empresa se ve obligada a cancelar tres pagos diferenciados a una misma persona, al cancelar dividendos y dietas, en función del socio y directivo respectivamente, y un salario por su carácter de empleado.

[...] el socio dueño denota tener tres funciones dentro de su misma empresa, siendo estas la de accionista, la de miembro de la junta directiva y la de asalariado, caso que suele ser muy usual en empresas pequeñas e incluso de mayor tamaño, pues claramente, al ser el emprendedor, quien ha dado paso a la creación del negocio (Sánchez, 2020, párr.2).

La situación antes señalada, aunque no tiene relación directa con el tipo de empresa en virtud de su tamaño, suele ser más observable en pymes, ya que el poder administrativo y de toma de decisiones tiende a estar más concentrado en una misma persona y las pymes usualmente son creadas por una sola persona o pocos socios (González, 2004).

\section{Sala Segunda}

Esta entidad del Estado tiene especial interés en el proceso, pues, al presentarse la existencia del pago de un salario a una determinada persona, puede interpretarse que cualquier otro pago dado a esta misma persona podría ser considerado como parte del salario; tema observado así en la sentencia 00238-2008 de la Sala Segunda, que señala lo siguiente:

[...] a pagar las dietas, ello no le elimina el carácter de retribución percibida con motivo de la prestación del trabajo y si el actor recibió esas dietas con ocasión de la relación laboral, es salario al tenor de lo que dispone el artículo 162 del Código de Trabajo, por cuanto era una retribución que se pagaba al trabajador con ocasión del contrato de Trabajo, o sea que si bien recibió dicho estipendio por su participación en sesiones formales o informales como directivo (Sala Segunda, (2008, párr.10). 
El interés de este ente parece ser velar porque el salario sea pagado y reportado en su totalidad hacia el empleado, como si existiera la presunción de una discrepancia en el ejercicio de pagos diferenciados de dietas y dividendos hacia una misma persona que también devengue un salario.

Lo anterior denotaría una posible falencia en la certeza jurídica que se le pueda brindar al empresario, pues, aunque se tenga la documentación pertinente que sustente los pagos en cuestión, la interpretación de la Sala Segunda parece ser amplia en el sentido del alcance y entendimiento que este ente le pudiese dar al tema, incluso un poco contraria a la libertad que el empresario debe tener al gestionar su propia organización (Wheelen y Hunger, 2007).

\section{Caja Costarricense del Seguro Social (CCSS)}

Completamente en relación con el tema anterior, la CCSS muestra un interés similar al del Ministerio de Trabajo y la Sala Segunda, ya que su intención parece ser más enfocada a presumir que todo pago realizado a una persona que devengue un salario desde una determinada empresa es parte también del mismo salario. Lo anterior se observa en la siguiente cita:

(...) se deben de considerar y/o revisar todos los pagos que no sean salario ordinario, por ejemplo: salario en especie -gasolina, vehículo, teléfono celular-; opciones accionarias; incentivos por metas alcanzadas; etc. No es regla general que todos los pagos mencionados en el párrafo anterior sean considerados como parte del salario y por ende afecten el cálculo, pues se deberá revisar individualmente la estructura de cada uno de ellos para determinar si de acuerdo a las regulaciones y jurisprudencia locales estos lo serían (por ejemplo, los pagos en concepto de gastos por vehículo, teléfono o gasolina serán considerados como parte del salario si consisten en un monto fijo por período de tiempo, pero no lo serán si son reembolsados cada vez contra la presentación por parte del empleado de un reporte indicando las sumas exactas gastadas en cada período) (Lang y Asociados, 2020, párr.17-18).

Lo anterior hace mención, entonces, a una interpretación contraria a la posible prueba que el patrono de una persona que sea a la vez socio y directivo pudiese dar como justificación de que el pago de dividendos y dietas en efecto no son parte del salario. Se precisa así que el interés de la CCSS parece enfocarse en el eventual cobro de cargas sociales, el cual se daría bajo el supuesto de que las dietas y dividendos no son reales y que responden a un ardid de la sociedad para evitar cancelar las correspondientes cuotas laborales.

\section{Ministerio de Hacienda}

El Ministerio de Hacienda, como es definido en sus funciones básicas (Ministerio de Hacienda, 2018), vela por el cumplimiento y cobro de las obligaciones tributarias de los administrados, razón por la cual su intervención e interés en los procesos que conlleven la existencia de la triple funcionalidad empresarial radica en la fiscalización de que cada pago conlleve de manera correcta su correspondiente carga tributaria (Avendaño, 2017).

Así, se reitera que las dietas y los dividendos implican el pago de un $15 \%$ de tasa tributaria, cancelado por medio de retención en la fuente, mientras que el salario mayor a ochocientos cuarenta mil colones conllevaría, de igual forma por retención patronal, una carga tributaria del 10 \% hasta el 25 \% (Asamblea Legislativa de Costa Rica, 2019a), por lo cual una determinada combinación de los tres pagos podría significar más o menos pago del impuesto total aplicado a la misma persona física, pero con diferente hecho generador (Asamblea Legislativa de Costa Rica, 2020).

En este ministerio parece darse más bien un interés en la presunción de que, al detallar los tres pagos en cuestión a la misma persona (dietas, dividendos y salario), podría estarse frente a una especie de evasión o elusión fiscal (Torrealba, 2009), esto en aras de cancelar menos impuestos que los existentes si todo se considerase pago del salario únicamente.

\section{Interpretaciones jurídicas y prácticas}

Como bien logra observarse, al existir dos ramas del derecho implícitas en esta función triple, entiéndase la laboral y la tributaria, las interpretaciones desde cada una de ellas parecen ser distintas, a pesar de que la existencia de la figura analizada no encuentra prohibición expresa en el ordenamiento jurídico. Estas interpretaciones se precisan a continuación. 


\section{Laboral}

Desde el punto de vista laboral, la interpretación parece ser dada en función de que todo pago realizado a una persona por parte de una sociedad (entiéndase una empresa) debe ser interpretado como parte del salario (Lang y Asociados, 2020) o al menos ser analizado desde una óptica en la cual se parte del supuesto de que lo cancelado a una persona que se encuentre en planillas de la empresa debe ser considerado como parte del salario y donde parece que la carga de la prueba recae sobre el patrono en función de justificar el eventual pago de dietas y dividendos.

Dicha interpretación encuentra sustento en la sentencia número 00894-2004 de la Sala Segunda, en la cual se señala lo siguiente:

Las dietas son una forma de remuneración - distinta al salario- que utilizan los órganos colegiados, siendo el hecho generador la asistencia a las sesiones, de lo cual normalmente se levanta un acta, donde se debe indicar las personas presentes, las circunstancias de tiempo y lugar, los puntos principales de la deliberación, el resultado de la votación y el contenido de los acuerdos (tratándose de las juntas directivas de las sociedades anónimas, ello se encuentra estipulado en los artículos 252 y 260 del Código de Comercio). En el caso concreto, esos registros no fueron aportados a los autos, razón por la cual no puede tenerse por demostrado que las sumas percibidas por [...] lo hayan sido en concepto de dietas (Sala Segunda, 2004, párr.13).

En esta interpretación, se priva del pago a la persona y se genera una carga adicional a la empresa en términos de probar que los pagos por concepto de dietas encuentran su sustento en la celebración de las juntas directivas, indiferentemente de que se trate de la misma persona que reciba salario, porque se observa la no aceptación del pago efectuado de la dieta en cuestión.

Existe aquí una posible presunción de evasión hacia las cargas sociales derivadas de lo que hubiese sido un salario, pues, aun cuando pudiese darse una interpretación en la cual las dietas son consideradas como un elemento ajeno a la relación laboral, al darse la situación hipotética donde estas son canceladas a un directivo que también sea asalariado, se ocasiona el estado de incerteza jurídica en cuestión y queda abierta la interpretación casuística.

\section{Tributaria}

Para efectos tributarios, la interpretación parece orientarse más a la presunción de una eventual evasión o elusión fiscal por parte de la empresa (Torrealba, 2009); es decir, el Ministerio de Hacienda parece evaluar que la existencia de pagos diferenciados a una misma persona por concepto de dividendos, dietas y salario, aunque cada una, en forma independiente, conlleva las cargas tributarias antes señaladas, podrían significar un ardid empresarial para una cancelación menor del impuesto total.

Los temas anteriores encuentran referencia en la resolución número 31-2006 del Tribunal Fiscal Administrativo (2006), en la cual se señala lo siguiente:

Es claro a nuestro juicio, que la intención del legislador fue la de gravar con el impuesto previsto en el artículo 32 de la Ley del Impuesto Sobre la Renta cualquier ingreso o beneficio, independientemente de la forma que este adoptara para su retribución; es decir, que se incluye todo el conjunto de beneficios que una persona puede obtener por su labor o por estar a disposición del empleador. En este orden de ideas, es nuestro criterio que el beneficio de obtener acciones de la casa matriz por parte de los empleados de [...], según el plan al que se acojan, a precios que en ese momento implican una ventaja económica para el empleado, constituye una retribución o salario en especie para él, producto de su relación laboral con [...], y gravable en consecuencia con el impuesto al salario (Tribunal Fiscal Administrativo (2006, párr.6).

De lo anterior se rescata una interpretación contraria a la existencia real de las tres figuras (socio, directivo y asalariado) y más bien parece presumirse que estos pagos diferenciados se realizan para efectos de diluir el impuesto que se pagaría, si solamente se hiciera por medio de un salario.

Incluso, también en la sentencia 00555-2017 de la Sala Primera (2017) se hace mención a que el pago de dividendos a un socio debe ser validado según su condición específica con vista a los libros de la empresa. 
De igual forma que en la interpretación laboral, este análisis tributario genera una condición de incertidumbre en el empresario, ocasiona vacíos legales de relevancia y da pie a posibles interpretaciones abusivas, sobre todo en consideración del principio solve et repete (Wolters Kluwer, 2020).

Cabe señalar que el principio solve et repete se entiende como:

[...] aquel en virtud del cual se exige el pago previo de la obligación tributaria, de las sanciones pecuniarias o de cualquier otra obligación de pago derivada de la ejecución de un acto administrativo, como condición para la revisión bien en vía administrativa bien en vía jurisdiccional del acto administrativo que da origen a dichas obligaciones de pago (Wolters Kluwer, 2020, párr.2).

\section{Discrepancias en la interpretación}

Con base en los puntos anteriores, puede observarse una falta de congruencia en las interpretaciones jurídicas dadas a la triple funcionalidad del empresario, ya que, desde el punto de vista laboral, parece darse una presunción de que todo pago realizado a una misma persona física desde una misma sociedad implica la existencia de un único salario, pues se induce a creer que no pueden darse pagos por diferentes funciones y posiciones intrínsecamente distintas en una misma sociedad.

Debe señalarse que la posición de socio y de directivo no conllevan la existencia de una relación laboral, tal como señala Rodríguez (2018):

En estos casos, la relación es claramente mercantil y no existen derechos laborales. Sin embargo, pueden darse casos en los que, además de las tareas propias del órgano de administración, el socio realice otras más propias del trabajador, es decir, que habría un doble vínculo (laboral y mercantil) (Rodríguez, 2018, párr.6).

De forma que no podría interpretarse a priori que la existencia de dos o tres pagos por concepto de dietas y dividendos sean automáticamente una forma de eludir la responsabilidad de cancelar el salario de la persona, pues en la figura de la triple funcionalidad se parte del hecho de que la persona que recibe los tres pagos en cuestión tiene, en efecto, un salario, el cual carga todas las obligaciones correspondientes, y los pagos derivados de su condición de socio y directivo son generados por el ejercicio de sus funciones específicas en estas posiciones, debidamente respaldadas en la documentación referente a las actas del libro de asamblea de socios y el libro de actas propiamente.

Por otra parte, en cuanto a la interpretación desde el enfoque tributario, parece darse más bien una presunción de evasión de los impuestos a cancelar, tal cual se señala en la resolución número 069-2015 del Tribunal Fiscal Administrativo (2015), en la cual se indica:

[...] entre los argumentos que cita para reafirmar que no se presentaron los documentos que justifica el gasto se señala que se realizan registros en la Cuenta de Mayor Analítico (folios 241-242) registros tanto por pago de dietas a junta directiva como de dietas a socios, que colateralmente el análisis hecho, es válido rescatar que la recurrente no apartó un estudio que justifique el pago cuantioso en controversia, que se debe hacer un estudio formalizado o comparado con otra institución en donde la cuota sea razonable, moderada y fundamentada, por lo que no ha presentado un estudio técnico o estudio que justifique razonablemente el registro objetado. Así mismo se cuestiona el por qué se registraron pagos al señor […] quien es el asesor del cuerpo directivo de la recurrente -anexo 8-además de que se registraron pagos por ф 1764705,88 por concepto de dietas a cada socio hasta tres veces en un mes, cuando la junta solo sesionó 7 veces en el 2010, concretamente en fechas 23/10/2009, 14/04/2010, 04/06/2010, 15/07/2010, 10/12/2009, 22/01/2010 y 05/03/2010, lo cual no empata con la cantidad de registros en cada período, en el entendido de que las sesiones de junta directiva se realizan una vez al mes, no se demuestra que el gasto es por dietas ni que sea procedente. Ahora bien, con todo lo anteriormente transcrito queda claro para este tribunal que el motivo de rechazo del presente gasto fue por cuanto a criterio del ente fiscalizador no se le presentaron los documentos que justifique que son dietas a socios o que en caso de ser salarios estos se sometieron a la CCSS (Tribunal Fiscal Administrativo, 2015, párr.15). 
Parece darse así una interpretación por parte del Ministerio de Hacienda hacia la existencia de figuras donde se crean las tres posiciones, entiéndase socio, directivo y asalariado, de forma que la sumatoria de todos sus impuestos cancelados sea menor a aquel que se daría si todo se cancela como un único salario o bien únicamente como dietas o dividendos.

En ambos casos, sin duda parece existir un principio inmerso de presunción de mala fe por parte del empresario para con el Estado. Incluso, ambas aproximaciones pueden ser contrarias entre sí, pues, mientras que la primera busca la existencia de un único pago por concepto salarial, la segunda se enfoca más en el quantum final tributario.

Indiferentemente de la interpretación que se dé a cada caso en particular, el deber de probar la legitimidad y legalidad del pago por concepto de triple funcionalidad, dividido en los tres rubros en cuestión, recae sobre la sociedad, tema que no solo genera una incerteza jurídica, sino que, en términos tributarios y bajo una aplicación del principio solve et repete, podría dejar en estado de indefensión al patrono.

\section{Regulación actual}

En referencia a la regulación existente sobre esta figura de la triple funcionalidad, primero debe señalarse que esta no se encuentra expresamente prohibida por norma alguna, ni en el Código de Comercio, ni en el Código de Trabajo; es decir, no existe numeral alguno, ni articulado específico que prohíba de manera expresa que una persona cuente con la calidad de socio y miembro de junta directiva debidamente nombrado y a la vez asalariado de la misma sociedad.

Debe agregarse a lo anterior, tal cual sostiene Acedo (2013), que en todo el ordenamiento referente al derecho privado se sigue el principio de autonomía de la voluntad, señalando que puede realizarse todo aquello que no esté expresamente prohibido por ley. Bajo este análisis y en función de que no existe norma expresa en contra, no pareciera haber razón para la cual una determinada autoridad ministerial del país interprete que la existencia de la triple funcionalidad del empresario pueda ser contraria al derecho.

Es de interés señalar que incluso el artículo 181 del Código de Comercio indica de forma expresa que sí es posible y permitido que una misma persona ostente a la vez el cargo de socio y de miembro de la junta directiva:

Los negocios sociales serán administrados y dirigidos por un consejo de administración o una junta directiva, que deberá estar formada por un mínimo de tres miembros, quienes podrán ser o no socios y ostentar las calidades de presidente, secretario y tesorero (Asamblea Legislativa de Costa Rica, 2019b, párr.1).

Cabe también señalar que en el derecho comercial es permitida la analogía en la interpretación, por lo cual podría interpretarse, en función de la certeza jurídica que debería ser brindada al empresario, que ya que es posible la doble funcionalidad (socio-directivo), también es viable la triple función, al agregar al binomio anterior la posibilidad de ser también asalariado. Así se otorgaría una especial protección y certeza a esta figura, en aras de incentivar la creación de empresas.

También debe agregarse lo señalado en el artículo 187 del Código de Comercio (2019):

El consejo de administración, o quienes ejerzan la representación social, podrán, dentro de sus respectivas facultades, nombrar funcionarios, tales como gerentes, apoderados, agentes o representantes, con las denominaciones que se estimen adecuadas, para atender los negocios de la sociedad o aspectos especiales de estos y que podrán ser o no accionistas (Asamblea Legislativa de Costa Rica, 2019b, párr.1).

Es decir, parece que se da la potestad a la junta directiva de nombrar accionistas como gerentes, lo que da paso a interpretar que la triple funcionalidad sí es permitida.

El tema encuentra especial relevancia al ligarse al concepto de libertad de empresa, regulado en la Constitución Política (Asamblea Legislativa de Costa Rica, 1949) en el numeral 25: "Los habitantes de la República tienen derecho de asociarse para fines lícitos. Nadie podrá ser obligado a formar parte de asociación alguna” (párr.1), con especial refuerzo en el numeral 46 de la misma norma, que consagra este principio.

Por lo cual, se refuerza la idea de que la definición estratégica sobre cómo estructurar las posiciones en la empresa, entiéndase la sociedad mercantil en cuestión, debe ser potestad única del máximo órgano societario, sin tener la intromisión estatal, en temas que son enteramente competencia de los propios socios, respetando así la libertad de organización y gestión del proceso administrativo propio de las empresas (Wheelen y Hunger, 2007). 
Ahora bien, la discrepancia que podría darse en la interpretación al implementar la triple funcionalidad como una figura legalmente aceptada y sin objeto de intromisión o presunción de mala fe, se da por el concepto de ajenidad del contrato laboral (Fernández, 2014), pues uno de los principios adyacentes de esta relación contractual es precisamente “[...] cuando se da la traslación inicial de la titularidad de los frutos del trabajo" (Blanch et al., 2003, p. 283).

Es este quizás un elemento que podría presentar discrepancias en términos de la distribución del poder societario, pues quien supervisa y coordina la gestión estratégica de las gerencias es la junta directiva, nombrada por la asamblea de socios, y, de darse la triple funcionalidad, uno de estos socios también sería empleado y presentaría así una especie de autonombramiento. Esto también puede ser contrario al principio de la administración referente a la unidad de mando, el cual señala que una misma persona no debe tener dos jefaturas, lo cual repercute directamente en la gestión de recursos humanos (Puchol, 2007).

No obstante, la contrahipótesis señala que la relación contractual es con la sociedad como tal y cada figura es independiente de la otra; es decir, el ser miembro de junta directiva no imposibilita el ejercicio de funciones gerenciales o viceversa, situación aplicable también a los socios.

\section{CONCLUSIONES}

La triple funcionalidad del empresario es una figura teórica derivada de la aplicación práctica en la administración, el derecho laboral y el derecho comercial, en la cual una persona física ostenta de forma simultánea las calidades de socio, miembro de junta directiva y asalariado, lo cual conlleva los derechos derivados, así como las obligaciones tributarias y sociales que cada pago implica, entiéndase dividendos, dietas y salario.

La figura definida como triple funcionalidad empresarial es atinente a las ciencias administrativas; no obstante, su regulación debe ser dada desde un enfoque jurídico, de forma que se pueda brindar protección y seguridad al empresario nacional; esto desde una base proporcionada por una legislación sólida y precisa que brinde certeza jurídica al desarrollo de las empresas, así como a sus socios.

Aunque el funcionamiento societario dado por la existencia de la condición de socio, directivo y asalariado presentes en una misma persona es una figura observable en todo tipo de empresa, es más usual su observancia en empresas pequeñas, denominadas pymes, por lo cual su regulación y precisión clara es fundamental para este tipo de organización y evitar así más trabas y problemas a estas empresas, lo cual se tornaría a la vez en un incentivo a la función empresarial.

La legislación nacional vigente no prohíbe de forma expresa la figura de la triple funcionalidad del empresario y, bajo la aplicación del principio de autonomía de la voluntad, esta debe ser permitida; con más razón todavía basada en el hecho de que el Código de Comercio permite de forma expresa el binomio socio-directivo, por lo cual, en forma análoga, la triple función también debe ser viable.

$\mathrm{Al}$ no estar expresamente regulada la triple funcionalidad del empresario, su aceptación por parte de las autoridades del país, en las ramas laboral y tributaria, queda totalmente sujeta a una interpretación casuística y subjetiva, por lo cual, su regulación se torna imperativa, en aras de brindar certeza jurídica y seguridad en el desarrollo de negocios y creación de empresas en el país.

Las interpretaciones dadas a esta figura parecen ser basadas en elementos valorativos de corte individual, es decir, sujetos a cada hecho y en la calidad de la evaluación realizada, lo cual genera una carga adicional al empresario nacional a efectos de probar la legalidad de los pagos hechos por los tres conceptos detallados (dividendos, dietas y salarios) a una misma persona. La regulación permitiría generar mejores marcos de acción empresarial.

Dicha regulación debe ser precisada mediante la estipulación expresa de la permisividad como una figura de uso habitual en las empresas nacionales, particularmente en las empresas familiares o de capital propio, pues es común y entendible que el empresario sea el dueño, quiera gestionar estratégicamente su negocio desde la junta directiva y además trabajar en ella. 


\section{Propuesta de regulación}

Con base en las ideas expresadas en los párrafos anteriores, se propone la regulación y permisividad expresa de la triple funcionalidad en el ordenamiento jurídico, partiendo de que, al ser esta figura dada en sociedades mercantiles y al estar expresamente permitido el ser socio y directivo a la vez, se sugiere que su regulación expresa se presente en el Código de Comercio también para el asalariado que ostente las dos posiciones anteriores.

Para efectos de la propuesta de regulación, se sugiere adicionar al artículo 187 del Código de Comercio un párrafo que señale lo siguiente:

Se permite la triple funcionalidad de la persona física en las sociedades mercantiles con operación y debidamente inscritas en el registro correspondiente, para que una persona física pueda ostentar simultáneamente las calidades de socio, miembro de junta directiva y asalariado, esto sin perjuicio de los requisitos legales y cargas tributarias que cada posición conlleve.

Derivado de la eventual regulación y pertinencia de esta figura en el ordenamiento jurídico nacional, lograría otorgarse así una mayor seguridad jurídica a los emprendedores, sobre todo a aquellos que desarrollen una empresa con su capital propio y que, con justo motivo, no son únicamente dueños, sino que desean ejercer un control estratégico desde la junta directiva y a la vez desempeñar funciones operativas desde puestos gerenciales. 


\section{REFERENCIAS}

Acedo, A. (2013). Introducción al Derecho Privado. Dykinson.

Asamblea Legislativa de Costa Rica. (1949). Constitución Política.

Asamblea Legislativa de Costa Rica. (2019a). Ley del Impuesto sobre la Renta.

Asamblea Legislativa de Costa Rica. (2019b). Código de Comercio.

Asamblea Legislativa de Costa Rica. (2020). Código de Normas y Procedimientos Tributarios.

Avendaño, M. (2 de octubre de 2017). EF Explica: Cómo declarar y pagar el impuesto sobre la renta. El Financiero. https://www.elfinancierocr.com/economia-y-politica/ef-explica-como-declarar-y-pagar-el-impuesto-sobre-larenta/B75JZMI52BC33LN3VBYZZD6JDA/story/

Blanch, J., Espuny, M., Gala, C., y Martín, A. (2003). Teoría de las relaciones laborales. Ediciones UOC.

Cabanellas, G. (2001). Compendio de Derecho Laboral. Tomo 1. Editorial Heliasta.

Fernández, L. (2014). Derecho individual del trabajo. Universidad Nacional de Educación a Distancia.

Goerlich, J., Ortega, J., García, M., Guamán, A., López, M., y López, E. (2010). Contratación laboral y tipos de contrato: Criterios Jurisprudenciales. Lexnova.

González, O. (2004). PYMES: Un componente importante del sector productivo en Costa Rica. Editorial de la Universidad de Costa Rica.

Herrero, J. (2012). Administración, gestión y comercialización en la pequeña empresa. (3ra ed.). Ediciones Paraninfo S.A.

Lang y Asociados. (2020). Legislación Laboral en Costa Rica. https://www.langcr.com/esp/legislacion_laboral.html.

Llompart, M. (2007). El salario, concepto, estructura y cuantía. Universidad de Valencia, Wolter Kluver.

Ministerio de Hacienda de Costa Rica. (2018). Información general, misión, visión y valores institucionales.

http://www.hacienda.go.cr/contenido/20-mision-vision-y-valores-institucionales

Monge, I. (2014). Curso de Derecho Comercial. Editorial Investigaciones Jurídicas.

Puchol, L. (2007). Dirección y gestión de Recursos Humanos (7ma ed.). Diaz de Santos.

Rodríguez, M. (8 de marzo de 2018). Los diferentes vínculos entre la sociedad y los socios que trabajan para la misma. Diario Jurídico. https://www.diariojuridico.com/diferentes-vinculos-entre-sociedad-y-socios-que-trabajan-para-la-misma/

Sala Primera. (2017). Sentencia 00555-2017. Poder Judicial: Costa Rica.

Sala Segunda. (2004). Sentencia 00894-2004. Poder Judicial de Costa Rica.

Sala Segunda. (2008). Sentencia 00238-2008. Poder Judicial de Costa Rica.

Sánchez, J. (2020). El emprendedor asalariado: independencia de persona jurídicas versus dependencia laboral conexa. La República. https://www.larepublica.net/noticia/el-emprendedor-asalariado-independencia-de-personasjuridicas-versus-dependencia-laboral-conexa

Sansonetti, C. (2020). Dividendos: exención y requisitos para su procedencia. El Observador. https://observador.cr/ dividendos-exencion-y-requisitos-para-su-procedencia/

Torrealba, A. (2009). Derecho tributario: principios generales y derecho tributario material. Editorial Jurídica Continental.

Tribunal Fiscal Administrativo (2006). Resolución número 31-2006. Poder Judicial: Costa Rica

Tribunal Fiscal Administrativo (2015). Resolución número 069-2015 Poder Judicial: Costa Rica

Wheelen, T., y Hunger, D., (2007). Administración estratégica y política de negocios. Conceptos y casos (10ma ed.). Pearson Education.

Wolters Kluwer. (2020). Solve et repete. https://guiasjuridicas.wolterskluwer.es/Content/

Documento.aspx?params =H4sIAAAAAAAEAMtMSbF 1 jTAAAUMTC1MDtbLUouLM_

DxbIwMDCwNzIoOQQGZapUt-ckhlQaptWmJOcSoAlx_FVzUAAAA=WKE 